\title{
Relationship between Stress and Educational Performance of University Students: A Correlational Research Study
}

a Sabiha Iqbal, ${ }^{\text {b }}$ Muzammila Akram, ${ }^{\mathrm{c}}$ Irem Mushtaq

${ }^{a}$ Assistant Professor, Department of Education, The Islamia University of Bahawalpur, Punjab, Pakistan. Email: sabiha.iqbal@iub.edu.pk

${ }^{\mathrm{b}}$ Assistant Professor, Department of Educational Training, The Islamia University of Bahawalpur, Pakistan Email id: muzammila.akram@iub.edu.pk

${ }^{\mathrm{c}}$ Assistant Professor, Department of Education, The Islamia University of Bahawalpur, Punjab, Pakistan Email: irem.mushtaql@iub.edu.pk

\begin{tabular}{l}
\hline ARTICLE DETAILS \\
\hline History: \\
Accepted 30 October 2021 \\
Available Online December 2021
\end{tabular}

\section{Keywords:}

Educational Performance;

University Students; Academic

Stress; Psychological Stress;

Correlational Research Study

\section{JEL Classification:}

I21, P27

DOI: $10.47067 /$ real.v4i4.198

\begin{abstract}
Almost every student experiences stress during his or her academic career. Academic stress has several health-related implications and has an impact on study and learning ability. The present study aimed to analyze the association between stress and educational performance of university students. Psychological, bodily, and behavioral difficulties are common because of such stress. Correlation research design was applied to achieve the objectives of this stud. Total 296 students were selected randomly from three departments (Education, Chemistry and English) of the Islamia University Bahawalpur. For the accomplishment of current study's objectives, data was collected via using a questionnaire and analyzed using SPSS. Descriptive statistics Pearson correlation test was applied to gain the results. The current study examined that majority of students are facing stress. The results also explore that physical and psychological stress have negative effects on academic achievement of students. It has been found that student's mental health has an impact on their academic performance. Therefore, it is recommended that the university should organize the programs which can help to detect and reduce the effect of stress among students.
\end{abstract}

(C) 2021 The authors. Published by SPCRD Global Publishing. This is an open access article under the Creative Commons AttributionNonCommercial 4.0

Corresponding author's email address: muzammila.akram@iub.edu.pk

\section{Introduction}

Students face many difficulties in achieving educational goals. Stress is a common issue among university students. It is true that the environment of higher education may be demanding. Professional organizations and educators are becoming more aware of the existence of stress and its negative impacts on academic attainment. It was found that stressful situations among students become the cause of many issues like skiving, unethical attitude, and poor educational performance (Hayble, 2016). 
Stress can cause both positive and negative emotions. When handled properly, stress can motivate people to take more action, which can lead to greater success; however negative emotions can cause health problems such as headaches, abdominal discomfort, insomnia, high blood pressure, and even stroke. The obstacles faced by university students that are thought to cause stress are referred to as stressors in this study. The degree to which students endure tensions, anxieties, pressures, and anxiety while pursuing their academic pursuits in universities is referred to as their stress level (Shield, 1995). Teachers frequently put emphasis on the acquirement of knowledge; hence they frequently overlook students' psychological needs during the teaching process, resulting in psychological stress and learning difficulties for pupils. Furthermore, learners might experience unusual emotions such as fear, concern, annoyance, abasement, melancholy, and so on. If proper well-timed counseling is not provided by schools, instructors, and parents, or if they cannot take appropriate assistance from their peers or family members, the uncertainty of such emotions develops unusual behavior. Which then affects students' learning accomplishments and adjustment ability (Liu \& Lu, 2012).

Academic stress is defined as anything that places additional demands on a person's ability to cope, most commonly the pressure of education. Studies examined that approximately all the students have to face educational challenges (Sahu, 2016). There are many reasons which create a stressful situation, for example, long school schedules, poor family status, demands from family and uncooperative educational environment, and poor educational performance (Liu \& Lu, 2012). Most students were concerned about their academic achievement. Examination anxiety, ineffective teaching methods, teacher-student interactions, severe academic workloads, and bad physical classroom conditions all add to students' stress levels. Depression, anxiety, loss of interest or motivation, drowsiness, attention issues, absenteeism, despondency, hunger fluctuations, tardiness, and mood swings are all indicators of academic stress. Exam pressure on students is increased by poor study habits, coping skills, and last-minute studying before tests. Anxiety, headaches, sleeping disorders, depression, and high blood pressure are all symptoms of environmental stress (Ahmad, Thawabieh, Lama \& Qaisy, 2012).

The term "environment" refers to the various circumstances that influence a student's academic achievement. Whether it's a physical or socio-physical setting, all environmental factors have a direct or indirect impact on learners' achievements (Ikealo et al., 2018). Relationship tension in students' life is caused by roommate conflict, college mate conflict, school mate conflict, and fights with friends. Because of the transitional character of university life, university students are more likely to be stressed. They'll have to get used to staying away from home. Maybe, in the beginning, they will be able to strike a balance between academic accomplishment and a different social milieu. These everyday stresses do not produce anxiety on their own. The relationship between the stressor and the person's perception and response to it causes stress. Individuals' capability to properly deal with stressful events or circumstances may determine the amount of stress they experience (Sindhu, 2016). Most of the high school and college students were obliged to participate in extracurricular activities such as choruses, clubs, athletics, band, and volunteer work. Academic pressure causes stress even when students have enough free time to participate in extracurricular activities. Students' extracurricular activities are impacted by cynicism, poor study habits, sleeping disorders, and emotional tiredness. Parental pressures in students' lives are increased by parent-child conflicts and separation from family (Sharma \& Pandey, 2017).

There is a link between stressful life events and poor academic performance among college students, according to research, as well as a link between stress and health-related quality of life (Misra \& McKean, 2000). Stress has a negative impact on both psychological and physical health, therefore it's 
no surprise that stress is one of the most common health factors affecting students' academic performance (Dwyer \& Cummings, 2001). Different studies explored that the students who have physical health issues and dissatisfaction with their studies have a high level of stress. According to the findings, female students are more influenced by homework and school-related stress than male students (Banerjee \& Duflo, 2011).

One of the most essential factors in the development of psychological issues is one's social setting. A more recent study investigated how a student's social setting could cause stress (Dusselier et al., 2005). Researchers discovered that shy students could not participate in educational and other activities because of their stressful conditions. Stress, along with sleep deprivation and substance usage, is linked to collegiate depression, according to the same study. The previous study's findings revealed that stress had an impact on academic achievement. The presence of stress may have an impact on the academic performance of students. Therefore, such kind of stress becomes the cause of the low level of educational performance of students. The students, who have a lot of stress, could not be able to manage their educational activities, time, and finances and feel difficulty in achieving academic tasks. So, these are the significant negative effects of stress in accomplishing educational tasks (Sharma \& Pandey,2017).

Students have their best energy level in college and universities but stress spoils their abilities and crucial years. Students who struggle to manage stress, have a positive influence on academics and behavior (Sindhu, 2016). Stress can have an impact on learning and memory. Although a healthy amount of stress can increase performance, too much stress can cause physical and mental health problems, lower self-confidence, and influence learners' educational performance. Stress is a normal part of life; however, it is linked to a variety of issues such as medical trauma, burns, and emotional arousal (Franken, 1994). When things change in our lives, we adjust our behavior to meet the new scenario. Stress has a noteworthy effect on our mood, sense of well-being, behavior, and health. The prevalence of stress-related activities among university students could imply that university environments expose students to pressures that eventually lead to stress. This has a deleterious impact on physical, cognitive, and psychological health (Rafidah, 2009).

On the one side of the coin, it has been suggested that university's stressful settings are likely to result in a drop in educational performance, as seen by low marks and failure to finish class assignments (Cabot, 2015). On the other side of the coin, several research studies have been unable to establish a link between stress and poor academic performance (Einstein, 2016). Stress is a mental state which creates obstacles in attaining educational tasks and positive behavior of students. University students are considered more civilized people of society. Therefore, they must manage their traumatic conditions to spend healthy lifestyle (Sindhu, 2016). Despite all that, when a child grasps the stage of adolescence, he faces different types of people, circumstances and so many compressions. Academic stress has been linked to several negative results, including physical sickness and mental health problems (Misra et al., 2000). Stress is considered one of the most serious challenges faced by university students, and its consequences can be seen in their social, academic, and emotional health.

Therefore, the present study was adopted to investigate the following objectives:

- To identify the academic, physical, and psychological stress of university students.

- To find out the relationship between the academic, physical, and psychological stress of university students with their educational performance. 


\section{Research Design}

Correlational research design was adopted for this quantitative study to identify the relationship between academic achievement and stress level of students. For attaining the objectives of the study researcher had rely on questionnaire. The current study was delimited to the students of Islamia University Bahawalpur Pakistan. The 296 students were selected from three departments (Education, Chemistry and English) by applying simple random sampling.

\subsection{Research Instrument}

Questionnaire for students based on three different factors that's highly caused of stress such as academic, psychological, and physical. The 13 items were related to academic stress, 11 items were allied to psychological stress and 9 items were linked to physical stress. All the items constructed on a fourpoint scale (1. Never, 2. Rarely, 3. Sometimes, 4. Frequently). All these items measure the stress level of respondent.

\subsection{Validation of Research Instrument}

Research tool was constructed according to the objectives and literature review. To ensure validity of tool, it was comprehensively checked from the panel of experts and refined in the light of their recommendation. Reliability of questionnaire was statistically computed by Cronbach Alpha value that was 0.864 .

\subsection{Data collection}

The questionnaires were distributed among students personally and directed them about the purpose of study, and procedure to respond on scale against each item. They were requested to fill them totally and return it back.

\subsection{Data analysis}

After collecting the data, analysis was carried out by applying "statistical package for social sciences" (SPSS). The academic, physical, and psychological stress level of students were analyzed by using descriptive statistics. To discover the relationship of stress (academic, physical, psychological) with the academic achievement of students, correlation coefficient was applied.

\section{Results}

The first objective of the study was to identify the academic, physical, and psychological stress level of students. Descriptive statistics were applied to achieve this objective. Mean score 2.00 and above was taken as criterion of acceptance while explaining the data in this section. Results are given in table 1.

Table 1 Stress (academic, physical, and psychological) level of students

\begin{tabular}{|l|l|l|l|}
\hline Statistics & Academic Stress & Physical stress & Psychological stress \\
\hline Mean & 2.24 & 2.08 & 2.08 \\
\hline St. Deviation & .55 & .60 & .60 \\
\hline
\end{tabular}

Note: mean score is based on data collected on four-point scale 
Table 1 displays the student's responses regarding their stress (academic, physical, and psychological) level. Results illustrate that the mean score of academic stress (Mean 2.24, SD .55) is greater than physical stress (Mean 2.08, SD .60) and psychological stress (Mean 2.08, SD .60) of students. So, these results explore that academic stress is higher than physical and psychological stress among university students.

Table 2 Relationship between Academic Achievement and Stress level of students

\begin{tabular}{|l|l|l|l|l|}
\hline & Statistics & Academic Stress & Physical Stress & Psychological Stress \\
\hline $\begin{array}{l}\text { Academic } \\
\text { achievement }\end{array}$ & $\mathrm{R}$ & .002 & $-.133^{*}$ & $-.133^{*}$ \\
\hline & $\mathrm{sig}$ & .975 & .022 & .022 \\
\hline
\end{tabular}

Note: $\operatorname{sig}=$ significance Level, $\mathrm{r}=$ correlation coefficient

Table 2 discloses the data regarding the relationship between academic achievement and stress (academic, physical, and psychological) level of students. Correlation analysis reported in table 2 reveals that strong negative significant relationship exist between academic achievement and physical stress ( $r-.133^{*}, \mathrm{p}$ 0.022) and psychological stress $\left(\mathrm{r}-.133^{*}, \mathrm{p}\right.$ 0.022) of students but there is no significant relationship occur between academic achievement and academic stress ( $\mathrm{r} .002, \mathrm{p} .975$ ) of students. Therefore, it was concluded that physical and psychological stress of students decrease the educational performance of students.

\section{Discussion}

Academic stress was defined as anything that places additional demands on a person's ability to cope, most commonly academic stress. Almost every learner experienced stress during his/her academic career (Sharma \& Pandey, 2017). Long school schedules, poor socioeconomic status, and family educational background, unrealistic faith and requisites of instructors and guardians, poor academic achievement, and bad study habits were some of the main reasons that cause stress (Banerjee, 2011). Most students were concerned about their academic achievement. Exam anxiety, ineffective teaching methods, teacher-student interactions, severe academic workloads, and bad physical classroom conditions all add to students' stress levels. Depression, anxiety, loss of interest or motivation, drowsiness, attention issues, absenteeism, despondency, hunger fluctuations, tardiness, and mood swings were all indicators of academic stress. Exam pressure on students was increased by poor study habits, coping skills, and last-minute studying before tests. According to the findings, female students were more influenced by homework and school-related stress than male students. (Misra et al., 2000)

One of the most essential factors in the development of psychological issues is one's social setting. A more recent study investigated how a student's social setting could cause stress (Dusselier et al., 2005). Studies explored that the students could participate in educational activities actively who keep in healthy pressure. Stress, along with sleep deprivation and substance usage, was linked to collegiate depression, according to the same study. The previous study's findings revealed that stress had an impact on academic achievement. The presence of stress may have negative impact on educational accomplishment of students. So, anxiety became the cause of poor performance of students in education. According to the views of Linn and Zeppa (1984), depression had negative effects on educational achievement of students, and relationship with others. 


\section{Conclusion}

Present study was a healthier effort in developing better understanding towards the effects of stress in attaining educational performance of students at university level. The current study examined that majority of students were facing stress. The results also explored that physical and psychological stress had negative effects on academic achievement of university students. Therefore, it was concluded that the students could not perform well in education if they possessed physical and psychological stressful situation.

\section{Recommendations:}

Based on the finding of current study, it was recommended that

- University managements need to assess the stress level of their students and offer them appropriate mental health care and effective stress management techniques.

- The results of this study approve negative effects of stress on educational accomplishment of university students. So, there is need to conduct more research studies at other educational level of students.

- This research might give stakeholders with scientific data on stress levels to assist students in avoiding stress from the start.

- Data was collected through questionnaire in this study hence, qualitative observation and case study methods might be conducted to explore in depth issues regarding stress.

\section{References}

Aafreen. M. M, Priya. V, Gayathri. R (2018). Effect of stress on academic performance of students in different streams. Research Articles, India, Vol. 10, Issue. 9, ppt. 177.

Ahmad, Thawabieh, M. Lama, Qaisy, M (2012). Assessing Stress among University Students. American International Journal of Contemporary Research Vol. 2 No. 2.

Banerjee, A. V., \& Duflo, E. (2011). Poor economics: Rethinking poverty \& the ways to end it. Random House India.

Bassi, G.; Mancinelli, E.; Di Riso, D.; Salcuni, S (2021). Parental Stress, Anxiety and Depression Symptoms Associated with Self-Efficacy in Paediatric Type Diabetes: A Literature Review. Int. J. Environ. Res. Public Health, Vol. 18, No. 152 https:// doi.org/10.339o/ijerph18010152

Bhargava, D., Trivedi, H. (2018). A Study of Causes of Stress and Stress Management among Youth. International Journal of Management \& Social Sciences, vol. 11, No.3, pg. 108-117. http://dx.doi.org/10.21013/jmss.v11.n3.p1

Dusselier, L., Dunn, B., Wang, Y., Shelley iI, M. C., \& Whalen, D. F. (2005). Personal, health, academic, and environmental predictors of stress for residence hall students. Journal of American college health, 54(1), 15-24.

Dwyer, A. L., \& Cummings, A. L. (2001). Stress, self-efficacy, social support, and coping strategies in university students. Canadian Journal of Counselling and Psychotherapy, 35(3).

Einstein, A. (2016). the Creation and Conversion of Lightf. The Old Quantum Theory: The Commonwealth and International Library: Selected Readings in Physics, 91.

Franken, D. G., Boers, G. H., Blom, H. J., Trijbels, F. J., \& Kloppenborg, P. W. (1994). Treatment of mild hyperhomocysteinemia in vascular disease patients. Arteriosclerosis and thrombosis: a journal of vascular biology, 14(3), 465-470.

Zhao, Z., Tian, J., Sang, Y., Cabot, A., \& Liu, H. (2015). Structure, synthesis, and applications of TiO2 nanobelts. Advanced materials, 27(16), 2557-2582.

Haidar, S. A., De Vries, N. K., Karavetian, M., \& El-Rassi, R. (2018). Stress, anxiety, and weight gain among university and college students: a systematic review. Journal of the Academy of Nutrition 
and Dietetics, 118(2), 261-274.

Hayble-Gomes, E. E. (2016). The economic impact of deficient anti-money laundering program to a multinational bank (Doctoral dissertation, Walden University).

Linn, B. S., \& Zeppa, R. (1984). Stress in junior medical students: relationship to personality and performance. Journal of medical education.

Misra, R., \& McKean, M. (2000). College students' academic stress and its relation to their anxiety, time management, and leisure satisfaction. American journal of Health studies, 16(1), 41.

Rafidah, K., Azizah, A., Norzaidi, M. D., Chong, S. C., Salwani, M. I., \& Noraini, I. (20o9). Stress and academic performance: Empirical evidence from university students. Academy of Educational Leadership Journal, 13(1), 37.

Sahu, A., Yadav, N., \& Sudhakar, K. (2016). Floating photovoltaic power plant: A review. Renewable and sustainable energy reviews, 66, 815

Shield, T. W. (1995). Orientation dependence of the pseudoelastic behavior of single crystals of $\mathrm{Cu} \square \mathrm{Al} \square \mathrm{Ni}$ in tension. Journal of the Mechanics and Physics of Solids, 43(6), 869-895.

Sharma G, Pandey D (2017), Anxiety, Depression, and Stress in Relation to Academic Achievement among Higher Secondary School Students, International Journal of Indian Psychology, Vol. 4, No. 2, pg. 87, DOI:18.01.051/20170402,

Sindhu P (2016), Impact of Stress on Academic Achievement among Engineering Students, International Journal of Indian Psychology, Vol.4, Issue 1, No. 81, DIP:18.01.122/20160401,

Ikealo, D., Yemane, B. and Karvinen, I. (2018) The Level of Academic and Environmental Stress among College Students: A Case in the College of Education. Open Journal of Social Sciences, 6, 40-12) https://doi.org/10.4236/jss.2018.611004

Olape. O.R, Lasiele A.Y, Chiaka. A. E. (2018). Cues to ensure and assure a stress-free academic environment for students.

Liu \& Lu. (2017). Stress Level and Academic Performance of University Students in Kwara State. Journal of Higher Education. Vol. 9, No. 1, ppt. 103-112 DOI:http://dx.doi.org/10.4314/majohe.v9i1.9 http://ajol.info/majohe

Malik. M (2015)11 Assessing Level and Causes of Exam Stress among University Students in PakistanMediterranean Journal of Social Sciences MCSER Publishing, Rome-Italy .Vol .6, No 4, ppt.11 Doi:10.5901/mjss.2015.v6n4s1p11

Essel. G and Owusu.P (2017).Causes of students' stress, its effects on their academic success, and stress management by students. International Business 2 SEINÄJOKI UNIVERSITY OF APPLIED SCIENCES. PPT.82

Bukhsha.Q, Shahzad.A and Nisa.M (2011). A Study of Learning Stress and Stress Management Strategies of the Students of Postgraduate level: A Case Study of Islamia University of Bahawalpur, Pakistan. Procedia Social and Behavioral Sciences Procedia - Social and Behavioral Sciences. doi:10.1016/j.sbspro.2011.10.036

Acevedo. J.E. (2020). Time Management and Academic Stress in Lima University Students. International Journal of Higher Education. Vol. 9, No. 9. https://doi.org/10.5430/ijh

Ramlic. M, Hambalid. IM. (2019). Academic Stress and its Sources among First Year Students of Islamic Higher Education in Indonesia. International Journal of Innovation, Creativity and Change. Volume 5, Issue 4, ppt. 535. 